\title{
ANKARA İÇİN DETERMİNİSTİK DEPREM TEHLİKE ANALİi்
}

\author{
Bülent ÖZMEN ${ }^{1}$, Hüsnü CAN ${ }^{2}$ \\ ${ }^{1}$ Gazi Üniversitesi, Deprem Mühendisliği Uygulama ve Araştırma Merkezi, Ankara \\ ${ }^{2}$ Gazi Üniversitesi, Mühendislik Fakültesi, İnşaat Mühendisliği Bölümü, Ankara \\ bulentozmen@gazi.edu.tr, $\underline{\text { husnucan@gazi.edu.tr }}$
}

(Geliş/Received: 07.06.2013; Kabul/Accepted: 07.01.2016)

ÖZET

\begin{abstract}
Ankara ili genel olarak depremsellik ve deprem tehlikesi açısından güvenli bir yer olarak bilinir. Fakat son yıllarda meydana gelmiş olan depremler ve yapılan çalışmalar bunun böyle olmayabileceğini göstermeye başlamıştır. Bu nedenle güncel verilerin ve çalışmaların ışı̆̆ı altında bölgenin depremselliğinin ve deprem tehlikesinin yeniden gözden geçirilmesi gerekmektedir. Çalışmanın amacı, deterministik (tanımsal) yöntemle Ankara ilinin deprem tehlikesini belirlemek ve deprem tehlike haritasını hazırlamaktır. Bu çalışma ile deterministik yöntem kullanarak, on dört kaynak bölge ve iki farklı azalım ilişkisinden yararlanarak ana kayada oluşabilecek maksimum yer ivmeleri hesaplanmış ve Ankara il sınırları içinde oluşabilecek maksimum yer ivme değerlerinin $0,1 \mathrm{~g}$ ile $0,6 \mathrm{~g}$ arasında değişebileceği bulunmuştur.
\end{abstract}

Anahtar Kelimeler: Ankara, deprem tehlikesi, deterministik yöntem

\section{DETERMINISTIC SEISMIC HAZARD ASSESSMENT FOR ANKARA, TURKEY}

\begin{abstract}
Mostly, The province of Ankara is known as a safe place in terms of seismicity and earthquake hazard. However, the earthquakes that have occurred in the recent years, and the studies have begun to show that it may not be such. Therefore, the seismicity and the seismic hazard of the region should be revised on the basis of current data and studies. The aim of this study is to determine the seismic hazard and to prepare an earthquake hazard map of Ankara by using the deterministic method. Deterministic seismic hazard analysis is applied for the province of Ankara and peak ground acceleration values at rock sites are determined by using two different the attenuation relationships and fourteen seismic source areas. In this study, peak ground acceleration values at rock sites is estimated to range from 0.1 to $0.6 \mathrm{~g}$ for Ankara province.
\end{abstract}

Keywords: Ankara, seismic hazard, deterministic method

\section{GÍRIŞ (INTRODUCTION)}

Ankara, Türkiye'nin İç Anadolu bölgesinde yer alır ve doğusunda Kırşehir, Kırıkkale, güneyinde Aksaray ve Konya, batısında Eskişehir ve kuzeyinde Bolu ve Çankırı illeri bulunur. Türkiye İstatistik Kurumu nüfus sayımına (2014) göre Ankara il sınırları içinde 5.150.072 kişi (Türkiye nüfusunun \%6,6's1) yaşamaktadır. $25,938 \mathrm{~km}^{2}$ alan üzerinde yer alan Ankara, Türkiye topraklarının \%3,3'ünü oluşturmaktadır. Ankara kent merkezi, Mülga Bayındırlık ve İskân Bakanlığı tarafından 1996 yılında yayımlanan ve bakanlar kurulu kararı ile yürürlüğe girmiş olan ve olasılık yöntemine göre hazırlanmış resmi deprem bölgeleri haritasına göre IV. derece deprem bölgesinde yer almaktadır. Yani 50 y1lda \%90 ihtimalle aşılmayacak yer ivmesi 0,1 g'dir [1]. Ankara il sinırlarının ise \%8'i I. derece, \%21'i II. derece, \%32'si III. derece ve \%38'i IV. derece deprem bölgesinde bulunmaktadır. 1945, 1947, 1963 ve 1972 tarihli eski resmi deprem bölgeleri haritalarında ise Ankara kent merkezinin bulunduğu bölge sırasıyla tehlikesiz, tehlikesiz, tehlikesiz ve IV. derece deprem bölgesinde gösterilmiştir. Türkiye'nin başkenti ve nüfus olarak İstanbul'dan sonra ikinci büyük ili olmasına rağmen Ankara için deprem 
tehlikesine yönelik çok az sayıda çalışma vardır. Bu çalışmalar sırası ile [2 - 14] tarafından yapılmıştır. Bu araştırmacılar tarafindan yapılan çalışmalar genel olarak Ankara ve yakın civarında meydana gelmiş olan depremler, bu depremlerin Ankara'ya etkileri ve aktif fayları belirlemeye yöneliktir. Bu yayınların hiç birinde Ankara ili için deterministik (tanımsal) yöntem kullanılarak deprem tehlike analizi yapılmamış ve bir deprem tehlikesi haritası hazırlanmamıștır.

Çalışmanın amacı, diri fay haritalarından ve deprem verilerinden yararlanarak, deprem üretme potansiyeli olan kaynak bölgeleri saptamak, tarihsel ve aletsel dönemde meydana gelmiş ve hasara neden olmuş depremleri ve büyüklük - sıklık ilişkisini kullanarak oluşabilecek maksimum deprem büyüklüklerini belirlemek ve uygun bir veya iki azalım ilişkisi kullanarak olası depremlerin oluşturabileceği maksimum yer ivmesi değerlerini hesaplayarak, Ankara ilinin deprem tehlike haritasını deterministik ve olasılık yöntemlerini kullanarak hazırlamaktır. Dünyanın değişik bölgeleri için deterministik yöntem kullanarak deprem tehlikesini belirlemeye yönelik birçok çalışma yapılmıştır. Örneğin Radulian vd., [15] tarafindan Romanya, El-Sayed vd., [16] tarafindan Misır, Bulajic ve Manic [17] tarafindan Sirbistan, Joshi vd., [18] tarafindan Kuzey Doğu Hindistan, Moratto vd., [19] tarafindan Yunanistan, Ganapathy [20] tarafindan Tamil Nadu (Hindistan), Tsapanos vd., [21] tarafindan Yunanistan'ın Corinth şehri, Tavakoli ve Amiri [22] tarafindan İran'ın kuzeyindeki Amol şehri, Shukla ve Choudhury [23] tarafindan Gujarat'ın büyük şehirleri, Wang vd., [24] tarafindan Tayvan için çalışmalar yapılmıştır. Türkiye ve Türkiye'nin farklı bölgeleri için ise; Kayabalı ve Akın [25] tarafindan Türkiye, Tosun vd., [26] tarafindan Fırat nehri havzasındaki büyük barajlar, Seyrek vd., [27] tarafindan Ceyhan havzasındaki barajlar, Tosun ve Seyrek [28] tarafindan Kızılırmak havzasındaki büyük barajlar, Seyrek ve Tosun [29] tarafindan Kızılırmak havzasındaki barajlar, Seyrek ve Tosun [30] tarafindan büyük beton barajlar için yapılan çalışmalar örnek olarak verilebilir.

\section{YÖNTEM (METHODOLOGY)}

Hasar ve can kaybına neden olabilecek büyüklükte bir depremin, belli bir yerde ve belli bir zaman aralığ içerisinde meydana gelme olasılığı "Deprem Tehlikesi" olarak tanımlanır. Zarar azaltma çalışmalarının temelini oluşturan deprem tehlikesi deterministik ve olasılık yöntemleri kullanılarak belirlenmektedir. Deterministik yöntemde deprem tehlikesi olasılığa dayalı olmadan, belirsizlik içermeyen bir matematik ifade kullanılarak, zaman bağımsız olarak yani depremlerin yinelenme periyotları dikkate alınmadan sadece maksimum deprem büyüklükleri göz önüne alınarak hesaplanır. Deterministik deprem tehlike analizinde öncelikle inceleme bölgesi civarındaki diri faylar ve bu fayların üretebileceği maksimum deprem büyüklükleri belirlenir, daha sonra bu fayların inceleme sahasına en yakın uzaklığı bulunur, depremin bu noktada oluşacağı varsayımı yapılarak ve uygun bir azalım ilişkisi kullanılarak maksimum depremlerin inceleme sahasında yaratabileceği yer hareketi parametreleri (şiddet, ivme, hız gibi) hesaplanır (Şekil 1). Bu çalışmanın çok sayıda alan için yapılması ve elde edilen değerlerin aynı büyüklükte olanlarının konturlanmasıyla da tehlike haritaları hazırlanır.

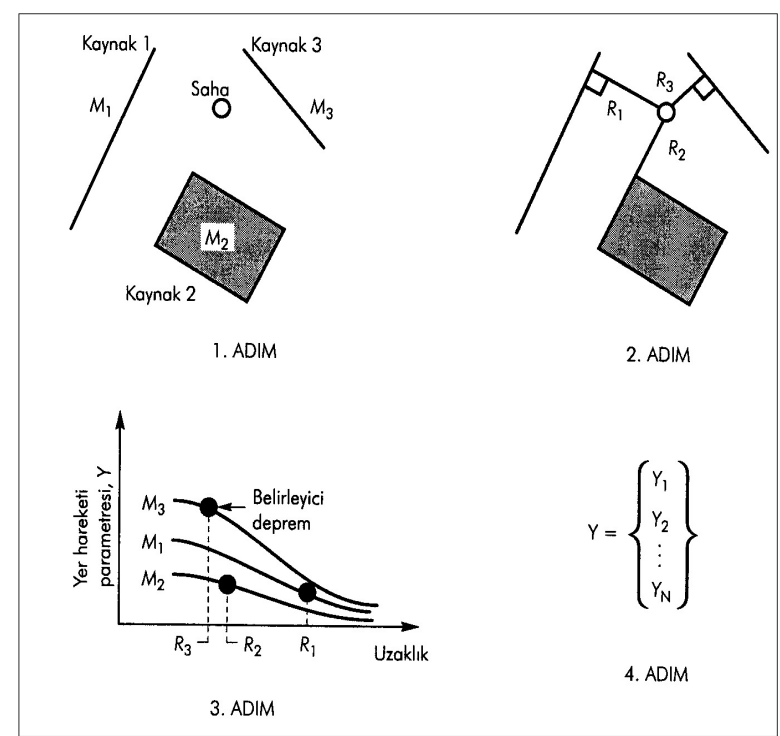

Şekil 1. Deterministik deprem tehlike analizinin aşamaları [31] (Steps of deterministic seismic hazard analysis)

\subsection{Kaynak Bölgeler (Seismogenic Zones)}

Deprem tehlike analizinin başlangıç noktası, etkilenme alanı olarak seçilen bölgedeki sismik kaynakların ve diri fayların konumlarının ve bunlara ilişkin sismisite parametre değerlerinin belirlenmesidir. İnceleme alanında birçok araştırmacı tarafindan bölgedeki diri fayları belirlemek için çalışmalar yapılmıştır [32 - 41] [7, 10, 14]. Kaynak bölgeler bu araştırmacılar tarafindan yapılmış olan diri fay haritalarından, tarihsel ve aletsel dönemde meydana gelmiş ve hasara neden olmuş depremlerden, 1900 - 2012 y1lları arasinda meydana gelmiş olan $\mathrm{M} \geq 3$ olan deprem verilerinden [42, 43], Erdik vd., [44], Gülkan vd., [45], TEFER, [46] ve DLH, [47] gibi Türkiye için yapılmış deprem tehlike haritaları hazırlanırken kullanılmış olan kaynak bölgelerden yararlanılarak belirlenmiştir (Şekil 2). Kaynak bölgelerde her bir noktanın deprem üretme potansiyelinin eşit olduğu varsayılır. Kaynak bölgelere ait bilgiler, bu bölgelerde tarihsel ve aletsel dönemde meydana gelmiş maksimum deprem büyüklükleri, büyüklük-sıklık ilişkisinden elde edilen a ve b parametreleri ve her kaynak bölge için detayları aşağıda verilen iki farklı yöntemle elde edilen maksimum deprem büyüklükleri Tablo 1'de verilmiştir. 


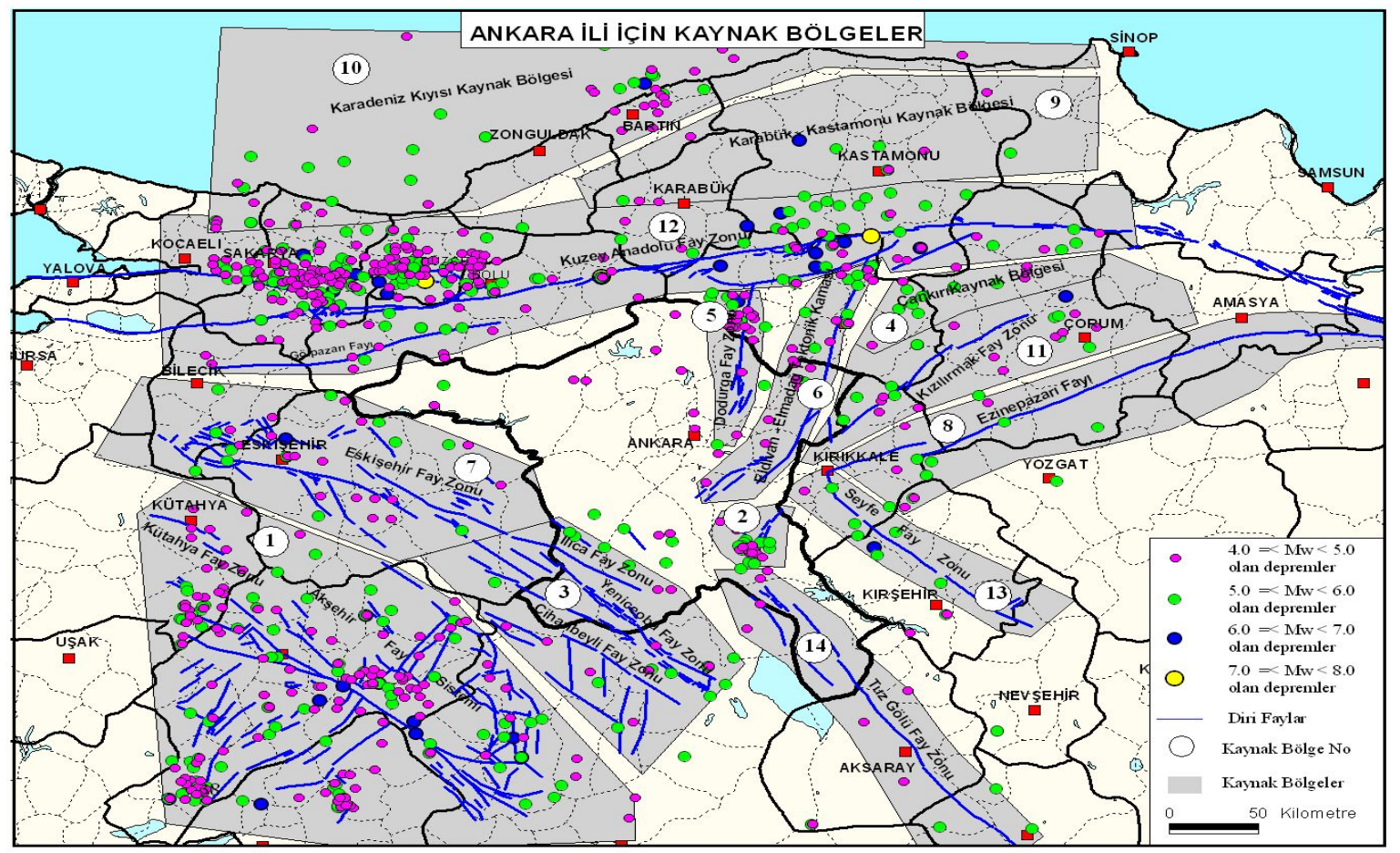

Şekil 2. Ankara ili için deprem üretme potansiyeli olan kaynak bölgeler (Seismogenic zones for Ankara province)

Tablo 1. Ankara ili için kaynak bölgeler ve bunlara ait parametreler (Seismogenic zones for Ankara province and its parameters)

\begin{tabular}{|c|c|c|c|c|c|c|c|c|c|c|c|}
\hline \multirow[b]{2}{*}{ No } & \multirow[b]{2}{*}{ Kaynak Bölge Adı } & \multicolumn{2}{|c|}{ Tarihsel dönemde } & \multicolumn{8}{|c|}{ Aletsel Dönemde } \\
\hline & & $I_{g m s ̧}$ & Tarih & Yer & $M_{g m}$ & Tarih & Yer & $\mathbf{a}$ & b & $\underset{\text { ks1 }}{\mathbf{M}_{\mathbf{m a}}}$ & $\begin{array}{c}\mathbf{M}_{\mathrm{m}} \\
\text { aks2 }\end{array}$ \\
\hline 1 & Akşehir Fay Sistemi & $\mathrm{X}$ & 1863 & Şuhut & 6,9 & 03.10 .1914 & Burdur & 6,26 & 0,86 & 7,3 & 7,5 \\
\hline 2 & Bala & - & - & - & 6,1 & 26.12 .2007 & Bala & 5,38 & 0,87 & 6,2 & 6,2 \\
\hline 3 & $\begin{array}{c}\text { Cihanbeyli - } \\
\text { Yeniceoba Fay Zonu }\end{array}$ & - & - & - & 5,6 & 16.01 .1918 & $\begin{array}{c}\text { Cihanbeyli } \\
\text { - Konya }\end{array}$ & 7,80 & 1,34 & 6,2 & 6,5 \\
\hline 4 & Çankırı & VIII & 12.05 .1844 & Osmancık & 5,8 & 21.11 .1942 & Corum & 4,50 & 0,70 & 6,5 & 6,5 \\
\hline 5 & Dodurga Fay Zonu & - & - & - & 6,1 & 06.06 .2000 & Dodurga & 5,19 & 0,84 & 6,2 & 6,2 \\
\hline 6 & $\begin{array}{c}\text { Eldivan - Elmadă } \\
\text { Tektonik Kaması }\end{array}$ & VIII & 28.09 .1881 & Çankırı & 5,8 & 09.03 .1902 & Çankırı & 6,47 & 1,08 & 6,0 & 6,5 \\
\hline 7 & Eskişehir Fay Zonu & VII & $? .10 .1862$ & Söğüt & 6,4 & 20.02 .1956 & Eskişehir & 7,29 & 1,16 & 6,5 & 7,0 \\
\hline 8 & Ezinepazarı Fay1 & IX & 1598 & Çorum & 5,6 & 17.10 .1970 & Amasya & 6,06 & 0,94 & 6,4 & 7,0 \\
\hline 9 & Karabük - Kastamonu & VII & 23.01 .1884 & $\begin{array}{c}\text { Kastamon } \\
\mathrm{u} \\
\end{array}$ & 6,1 & 26.10 .1945 & & 5,27 & 0,84 & 6,3 & 6,3 \\
\hline 10 & Karadeniz Kiyıs1 & VI & 1880 & Sinop & 6,5 & 03.09 .1968 & Amasra & 5,01 & 0,75 & 6,7 & 6,8 \\
\hline 11 & Kizılırmak Fay Zonu & VIII & 1075 & Çorum & 6,2 & 11.12 .1942 & Çorum & 5,87 & 0,95 & 6,2 & 6,5 \\
\hline 12 & $\begin{array}{c}\text { Kuzey Anadolu Fay } \\
\text { Zonu }\end{array}$ & IX & 03.09 .968 & $\begin{array}{l}\text { Çorum - } \\
\text { Amasya }\end{array}$ & 7,6 & 01.02 .1944 & $\begin{array}{l}\text { Gerede - } \\
\text { Bolu }\end{array}$ & 6,02 & 0,78 & 7,8 & 8,0 \\
\hline 13 & $\begin{array}{l}\text { Seyfe Fay Zonu } \\
\text { Kaynak Bölgesi }\end{array}$ & - & - & - & 6,7 & 19.04 .1938 & Kırşehir & 2,65 & 0,40 & 6,7 & 7,0 \\
\hline 14 & $\begin{array}{c}\text { Tuzgölü Fay Zonu } \\
\text { Kaynak Bölgesi }\end{array}$ & IX & 110 & Tuzgölü & 5,8 & 10.01 .1940 & Niğde & 4,90 & 0,81 & 7,0 & 7,3 \\
\hline
\end{tabular}

1 nolu kaynak bölge normal faylardan oluşan Akşehir fay sistemi, 2 nolu kaynak bölge normal fay olan Afşar ve Karakeçili fayları, 3 nolu kaynak bölge sağ yönlü doğrultu atımlı Cihanbeyli ve Yenice oba fay zonları, 5 nolu kaynak bölge sol yönlü doğrultu atımlı Dodurga fayı, 6 nolu kaynak bölge Eldivan-Elmadağ tektonik kaması, 7 nolu kaynak bölge doğrultu atımlı ve normal faylardan oluşan Eskişehir fay zonu, 8 nolu kaynak bölge sağ yönlü doğrultu atımlı Ezine pazarı fayı, 11 nolu kaynak bölge sol yönlü doğrultu atımlı Kızılırmak fay zonu, 12 nolu kaynak bölge sağ yönlü doğrultu atımlı Kuzey Anadolu fay zonu, 13 nolu kaynak bölge sağ yönlü doğrultu atımlı Seyfe fay zonu ve 14 nolu kaynak bölge de çok küçük oranda sağ yanal doğrultu atım bileşenine sahip yüksek açılı normal bir fay olan Tuz gölü fay zonunun etkisi altındadır. 4, 9 ve 10 nolu kaynak bölgeler herhangi bir fayla ilişkilendirilememiştir. Tablo 1'deki $M_{g m b}$ : Aletsel önemde (1900 yılı sonrası) gözlenmiş maksimum deprem büyüklüğünü, $I_{g m s ̧}$ : Tarihsel dönemde (1900 yılı öncesi) gözlenmiş maksimum 
deprem şiddetini göstermektedir. Maksimum deprem büyüklükleri her kaynak bölge için ayrı ayrı hazırlanmış olan büyüklük - sıklık ilişkisi $(\log N=a-$ bM) grafiklerinden yararlanılarak ve en küçük kareler yöntemi kullanılarak elde edilmiştir [48]. En küçük kareler yöntemi ile elde edilmiş olan eğrinin yatay ekseni yani büyüklük (Mw) eksenini kestiği yerdeki değer o kaynak bölgede oluşabilecek maksimum büyüklük olarak alınmış ve Tablo 1'de $\mathrm{M}_{\max 1}$ sütununda gösterilmiştir. Eskişehir fay zonu için 1956 yılında ve Tuzgölü fay zonu için ise 110 yılında meydana gelmiş depremlerin büyüklükleri maksimum deprem büyüklüğü olarak alınmıştır. Tablo 1'de $\mathrm{M}_{\max 2}$ sütununda her kaynak bölge için ayrı ayrı verilmiş olan maksimum deprem büyüklükleri ise Deniz [49] tarafindan önerilmiş olan $\mathrm{M}_{\max }=\left(\left(M_{m k s}^{g m}+0,5\right)+\right.$ $\left.\left(\mathrm{M}_{\mathrm{uzm}}\right)\right)$ / 2 ilişki kullanılarak elde edilmiştir. Burada $\mathrm{M}_{\max }$ : Maksimum deprem büyüklüğü, $M_{m k s}^{g m}$ : Kaynak bölgede gözlenmiş maksimum deprem büyüklüğü ve $\mathrm{M}_{\mathrm{uzm}}$ : Uzman görüşüne dayalı olarak belirlenmiş maksimum deprem büyüklüğünü ifade eder.

\subsection{Azalım İlişkileri (Attenuation Relations)}

Yer ivmesinin $\left(\mathrm{cm} / \mathrm{sn}^{2}\right)$ uzaklık ile ne şekilde azaldığ azalım ilişkileri kullanılarak belirlenmeye çalışılır. Genellikle azalım ilişkilerinden elde edilen ivme değerleri ana kayadaki ivme değerleridir ve birbirinden oldukça farklı sonuçlar verebilirler. Yer yapısına göre ivme değerleri ana kayadan yeryüzüne çıkıncaya kadar çeşitli değişikliklere uğrar. Bu çalışmada ivmenin sadece ana kayadaki azalışı göz önüne alınmıștır. Türkiye için şimdiye kadar İnan vd.,
[50]; Aydan vd., [51]; Gülkan ve Kalkan [52]; Kalkan ve Gülkan [53]; Ulusay vd., [54]; Beyaz [55] ve Yunatçı [56] tarafindan maksimum yer ivmelerini tahmin edebilmek için azalım ilişkileri geliştirilmiştir. Türkiye için geliştirilmiş olan bu azalım ilişkilerinden yararlanılarak $\mathrm{Mw}=7,4$ büyüklüğü ve değişik uzaklıklar için yer ivmeleri hesaplanarak Şekil 3'de gösterilmiştir. Şekil incelendiği zaman en düşük değerlerin Beyaz [55] azalım ilişkisinden, en yüksek değerlerinde İnan [50] azalım ilişkisinden elde edilmiş olduğu görülmektedir. Türkiye için geliştirilmiş olan bu yedi azalım ilişkisine göre ortalama değerler veren Gülkan ve Kalkan [52] azalım ilişkisinin bu çalışmada kullanılmasının uygun olacağ 1 düşünülmüştür. Elde ettiğimiz sonuçları diğer ülkeler için geliştirilmiş olan azalım ilişkileri ile kıyaslayabilmek için de Boore vd., [57] tarafindan geliştirilen azalım ilişkisinin kullanılmasına karar verilmiştir. $\mathrm{Bu}$ azalım ilişkisinin ağırlıklı olarak sismotektonik rejim açısından ülkemizin depremselliğini kontrol eden Kuzey Anadolu fay sistemini andıran batı ABD'deki deprem kayıtlarından yararlanılarak geliştirilmiş olması seçimimizin bu şekilde olmasına neden olmuştur. $\mathrm{Bu}$ iki azalım ilişkisi ve bunlara ait bilgiler aşağıdaki gibidir.

Boore vd., [57] tarafindan önerilmiş olan azalım ilişkisi

$\log (\mathrm{PHA})=-0,242+0,527(\mathrm{Mw}-6)-0,778 \ln$ $\left(R^{2}+h^{2}\right)^{1 / 2}-0,371 \ln (700 / 1396)$

Burada; PHA: Maksimum yatay ivme (g); R: Yüzey kırığına en yakın uzaklık (km); h : fiktif (varsayılan) odak derinliği $(\mathrm{km})(\mathrm{h}=5,57) ; 5,5<\mathrm{Mw}<7,5$ ve $\mathrm{R} \leq$

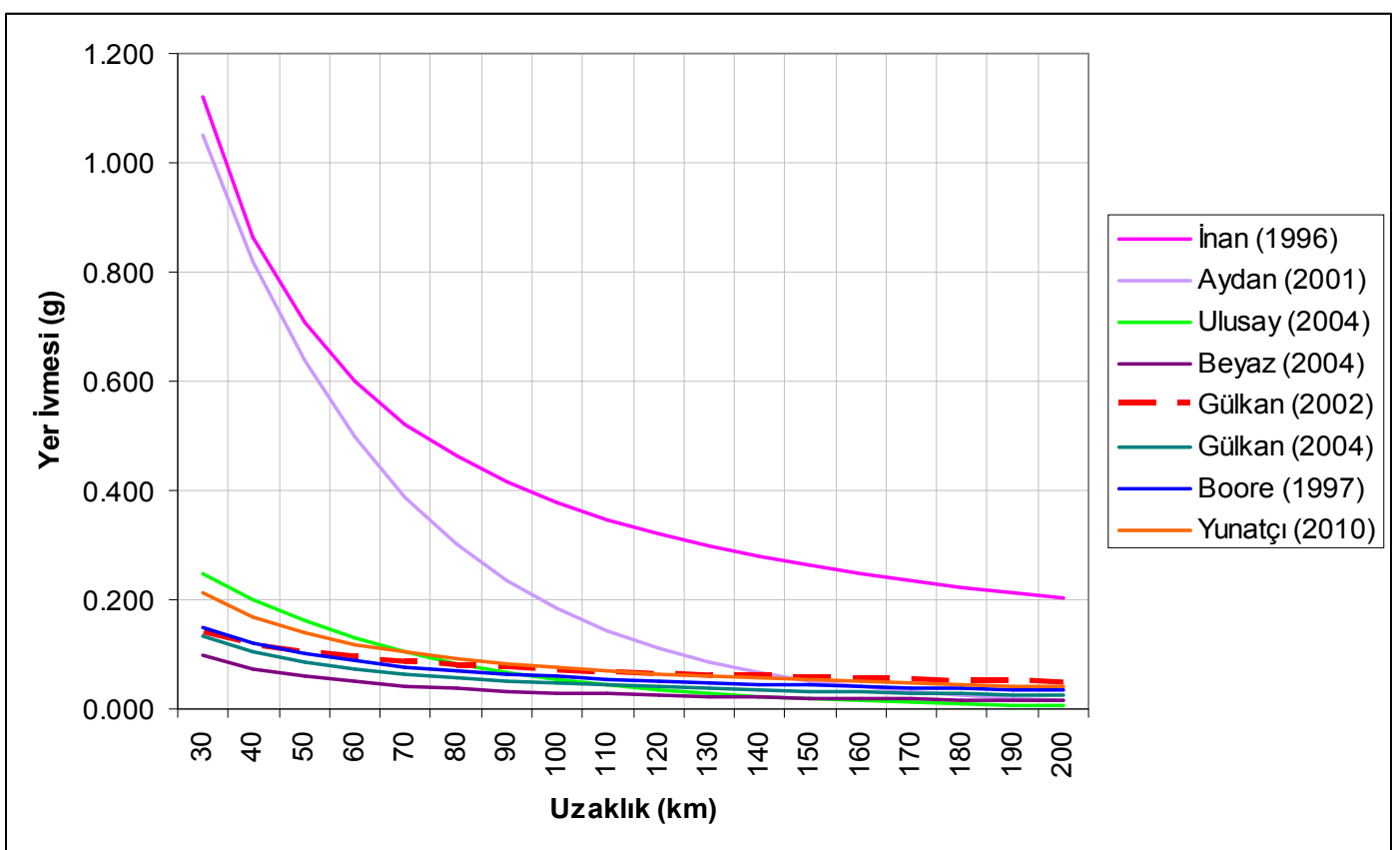

Şekil 3. Çeşitli azalım ilişkilerine göre yer ivmesinin uzaklıkla değişimi (Different attenuation functions are plotted with respect to distance for a magnitude of Mw:7,4) 


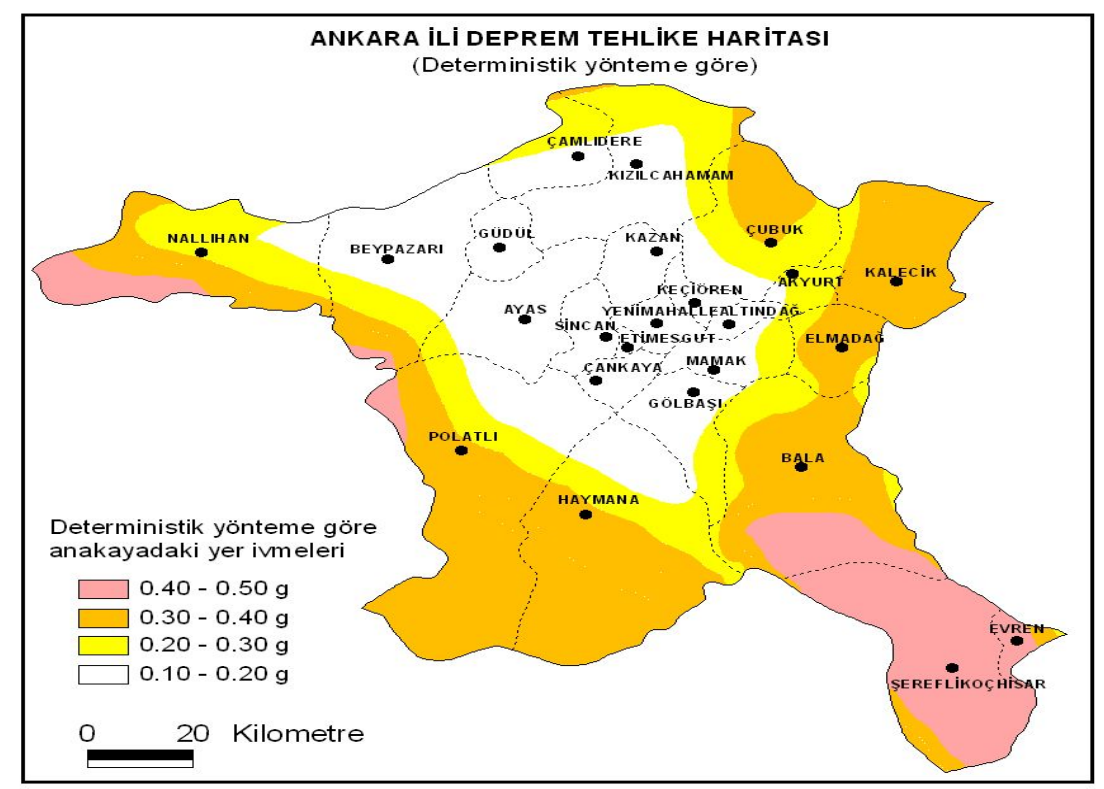

(a)

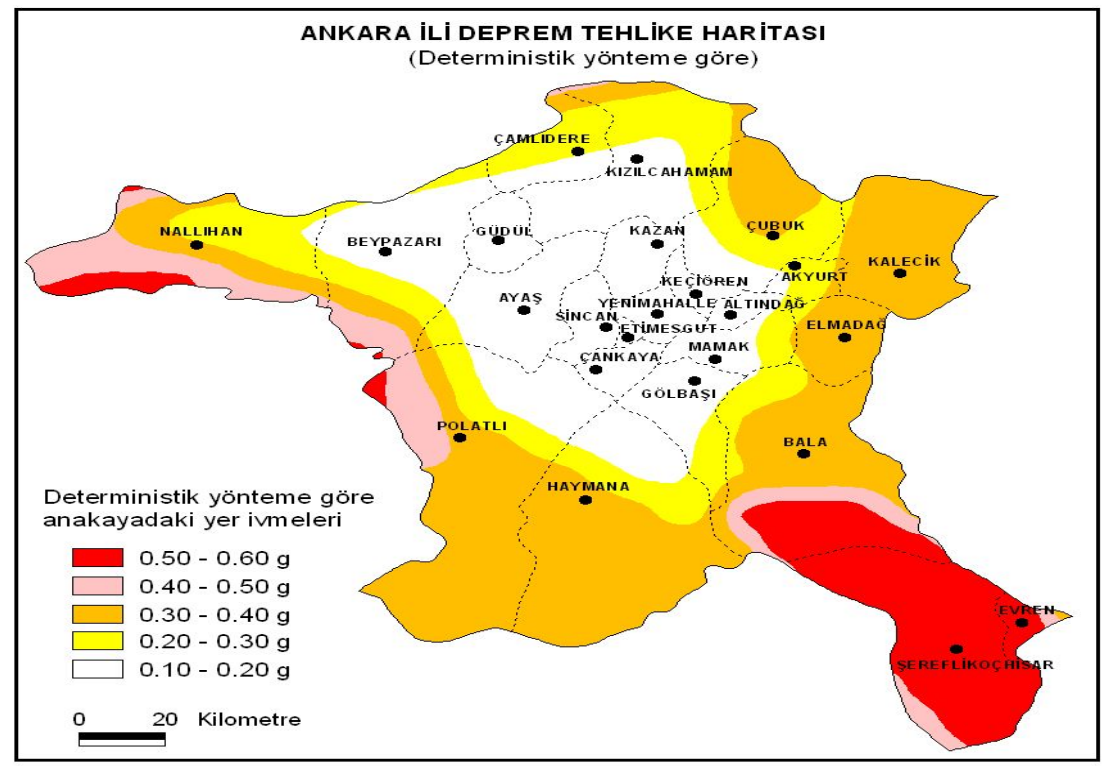

(b)

Şekil 4. Deterministik yönteme göre Ankara ilinin deprem tehlike haritası ((a) Gülkan ve Kalkan [52] azalım ilişsisine (b) Boore vd., [57] azalım ilişskisine göre) (Seismic hazard maps for Ankara by using the deterministic method ((a) according to Gülkan and Kalkan [52] (b) Boore et al., [57] attenuation relationships)

$80 \mathrm{~km}$ için geçerlidir. Mw : Moment büyüklüğü; Vs: Kayma dalgası hızı (700), (m/sn); Standart sapma $(\sigma)$ : 0,52 dir. Gülkan ve Kalkan [52] tarafindan önerilen azalım ilişkisi 1976 - 1999 yılları arasında Türkiye'de meydana gelmiş $\mathrm{Mw} \geq 5,0$ olan 18 depremin neden olduğu 47 yatay bileşenden elde edilen 93 yer hareketi kaydından yararlanarak elde edilmiştir.

LnPHA $=-0,682+0,253(\mathrm{Mw}-6)+0,036(\mathrm{Mw}-$ $6)^{2}-0,562 \ln (r)-0.297 \ln (\mathrm{Vs} / \mathrm{Va})$

Burada; PHA: Maksimum yatay ivme (g); R: Yüzey kırığına en yakın uzaklık (km); Mw: Moment büyüklügü; h: fiktif (varsayllan) derinlik (km) (=
4,48); Va = 1381(fiktif (varsayılan) hız); Vs = Kayma dalgası hızı $(700 \mathrm{~m} / \mathrm{sn}) ; \sigma=0,562$ (Standart sapma); $\mathrm{r}=$ $\left(\mathrm{R}^{2}+\mathrm{h}^{2}\right)^{1 / 2}$

\section{BULGULAR (RESULTS)}

Yukarıda belirtilen azalım ilişkileri ve Tablo 1'de verilen maksimum deprem büyüklüklerinden yararlanarak deterministik ve olasılık yöntemi kullanılarak değişik uzaklıklardaki yer ivmesi değerleri EZFRISK 7.52.0.1 yazılımı kullanılarak hesaplanmıştır. $\mathrm{Bu}$ yazılım iki boyutlu karelaj sisteminin her düğüm noktasındaki maksimum yer hareketlerini deprem kaynak bölge sınırlarındaki, 
azalım ilişkilerindeki ve deprem parametrelerine ilişkin belirsizlikleri dikkate alacak şekilde hesaplamaktadır. İnceleme sahası 0,1 derecelik aralıklarla artan bir ağa bölünmüş ve her düğüm noktasındaki (840 tane) maksimum yer ivmeleri daha önce açıklanmış kaynak bölgeler, azalım ilişkileri ve deprem parametrelerinden yararlanılarak belirlenmiştir. Her düğüm noktası için yer ivmeleri bütün kaynak bölgeler için hesaplanmış ve bulunan en büyük değer o noktanın yer ivmesi olarak kabul edilmiştir. Her düğüm noktası için hesaplanmış olan bu yer ivmelerinden yararlanılarak Ankara ili için deprem tehlike haritaları hazırlanmıştır. Hesaplamalar önce Gülkan ve Kalkan [52] tarafindan önerilen azalım ilişkisi kullanılarak ve Tablo 1'deki $\mathrm{M}_{\text {maks1 }}$ sütunundaki büyüklükler için, daha sonra $\mathrm{M}_{\text {maks2 }}$ sütunundaki büyüklükler için yapılmış ve elde edilen değerlerin ortalaması alınarak o noktadaki ivme değeri bulunmuştur. Aynı işlemler 840 nokta için yapılarak her noktada oluşabilecek ivme değerleri olasılık ve deterministik yöntem kullanılarak hesaplanmış, eşit değerde olanların birleştirilmesi ile deprem tehlike haritaları hazırlanmıştır (Şekil 4a, Şekil 5a). Daha sonra yukarıdaki işlemler Boore vd., [57] tarafindan önerilen azalım ilişkisi kullanılarak yapılmış ve elde edilen değerlerden yararlanarak Ankara ili için farklı deprem tehlike haritaları hazırlanmıştır (Şekil 4b, Şekil 5b).

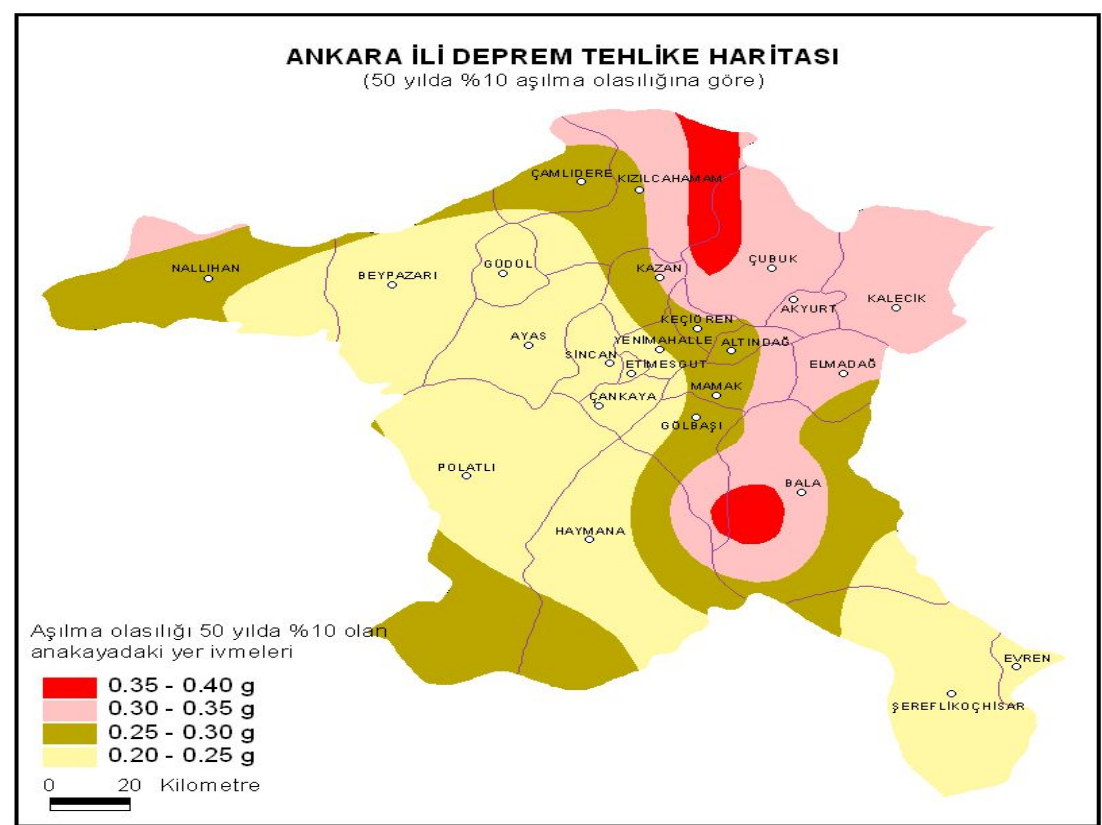

(a)

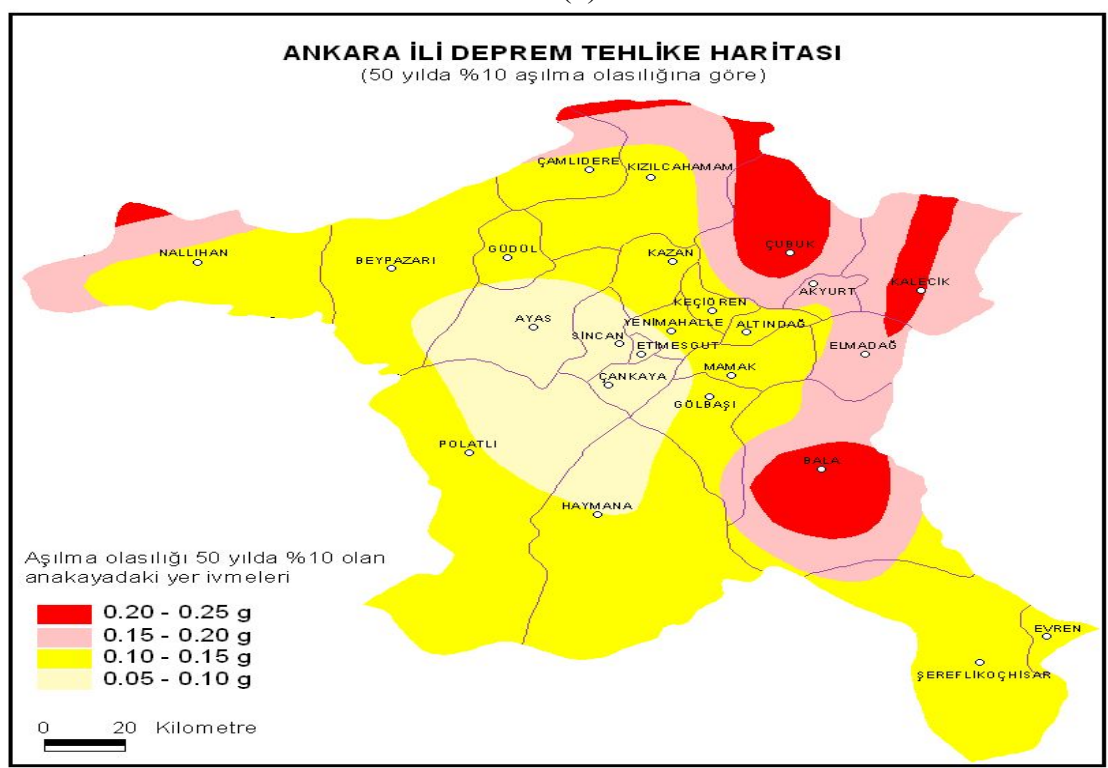

(b)

Şekil 5. Olasılık yöntemine göre Ankara ilinin deprem tehlike haritası ((a) Gülkan ve Kalkan [52] azalım ilişkisine (b) Boore vd., [57] azalım ilişkisine göre) (Seismic hazard maps for Ankara by using the probabilistic method ((a) according to Gülkan ve Kalkan [52] (b) Boore et al., [57] attenuation relationships) 


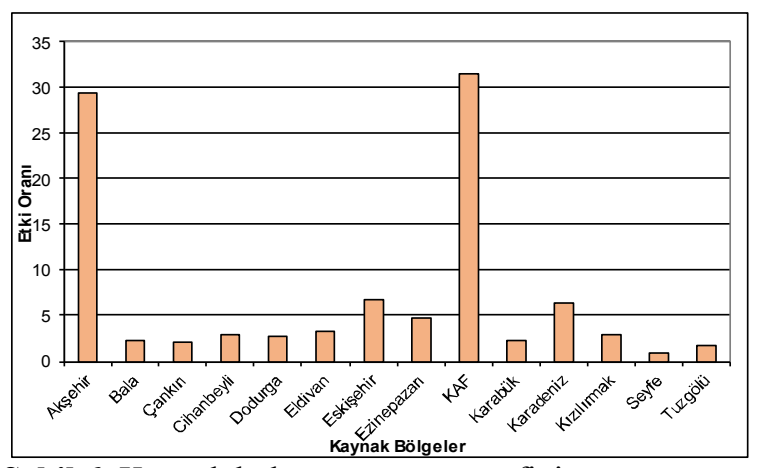

Şekil 6. Kaynak bölge ayrıştırma grafiği (The plot of the results of the deaggregation in terms of source areas)

Deterministik yöntemde depremlerin tekrarlanma periyotları, yıllık aktivite oranları ve yıllık kayma hızları dikkate alınmadan hesaplamalar yapılır. Bu nedenle deprem yinelenme periyodu oldukça uzun olan Tuzgölü fay zonu nedeniyle Şereflikoçhisar ilçesinde yer ivme değerleri oldukça yüksek çıkmıştır. $\mathrm{Bu}$ fay üzerinde yaklaşı 1000 - 2000 yılda bir meydana gelebilecek 7,3 büyüklüğündeki bir deprem nedeniyle oluşabilecek bu yer ivmelerinin 50 yıl, 100 yıl gibi ekonomik ömrü olan yapılarda kullanılması önerilmez. Deterministik yöntem kullanılarak elde edilen bu değerler sadece en kötü olasılıklar dikkate alınarak yapılan Deprem Senaryosu çalışmalarında kullanılabilir. Deprem tehlike analizi sonucunda hesaplanan değerler deprem kaynaklarının, kaynaklara bağlı bütün deprem büyüklüklerinin ve inceleme sahası ile kaynak bölge arasındaki uzaklıklarının ortak katkısını göstermektedir. Elde ettiğimiz değerlerden Ankara kent merkezinde (32.80

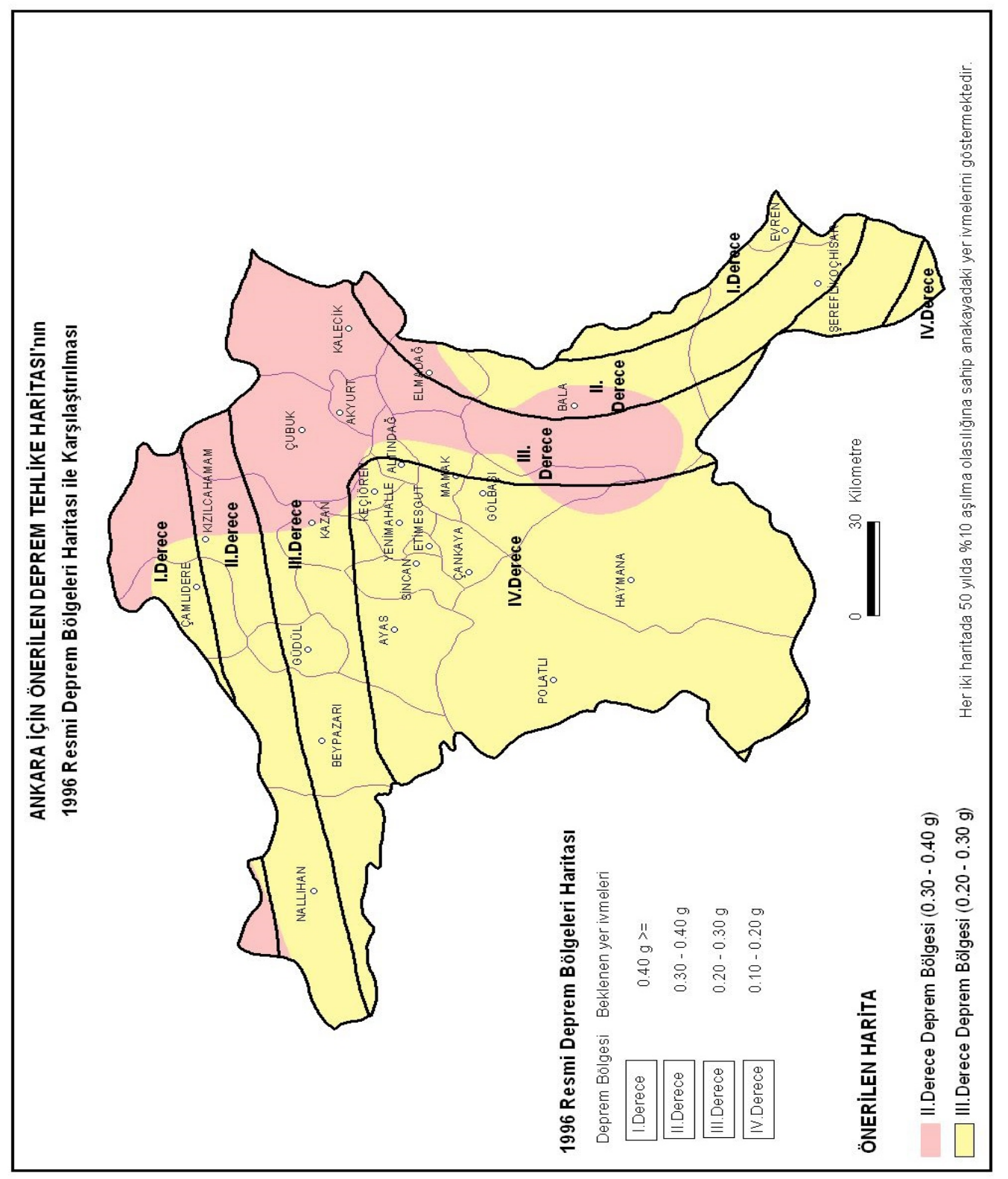

Şekil 7. Ankara ili için önerilen harita ve 1996 tarihli resmi deprem bölgeleri haritasının karşılaştırılması (A comparison of official seismic hazard map (1996) and proposed seismic hazard map for Ankara province) 
boylam, 40.00 enlem) beklenen yer ivmesi değerlerine en büyük katkıyı hangi kaynak bölgesinin sağladığını bulmak için ayrıştırma analizi yapılmıștır (Şekil 6). Şekil incelendiği zaman en büyük katkının Kuzey Anadolu fay sistemi ve Akşehir fay sistemi kaynak bölgelerinden kaynaklandığ́ görülmektedir. Ankara ili için yeni veriler ve gelişmeler 1şı̆̆ında hazırlanmış olan bu deprem tehlike haritalarından 50 yılda \% 10 aşılma olasılığına göre hazırlanmış olan haritanın Ankara il sınırları içinde yapılacak binalar için kullanılmasının daha uygun olacağ düşünülmektedir. $\mathrm{Bu}$ harita ve halen yürürlükte olan 1996 resmi deprem bölgeleri haritası, önerilen değişiklikleri daha net olarak görebilmek ve iki haritanın daha kolay kıyaslanabilmesini sağlamak için üst üste çakıştırılmış ve elde edilen harita şekil 7'de gösterilmiştir. İki haritayı daha sağlıklı ve iyi bir şekilde kıyaslayabilmek için sınıflandırmalar 1996 haritası baz alınarak yapılmıştır

\section{SONUÇLAR (CONCLUSIONS)}

Aktif tektonik çalışmalardan, tarihsel (1900 yılı öncesi) ve aletsel (1900 sonrası) dönemde hasara neden olmuş depremlerden, $\mathrm{M} \geq 3$ olan depremlerden ve daha önce yapılmış olan çalışmalardan yararlanılarak Ankara ilini etkileyebilecek ve depreme kaynaklık edebilecek 14 bölge belirlenmiştir. Bu kaynak bölgeler sırası ile Akşehir fay sistemi, Bala, Cihanbeyli-Yeniceoba, Çankırı, Dodurga, EldivanElmadağ tektonik kaması, Eskişehir fay zonu, Ezinepazarı fay zonu, Karabük-Kastamonu, Karadeniz kıyısı, Kızılırmak fay zonu, Kuzey Anadolu fay sistemi, Seyfe fay zonu ve Tuzgölü fay zonu kaynak bölgesi diye isimlendirilmiştir. Deterministik yöntem kullanılarak yapılan hesaplamalarda Ankara il sınırları içindeki maksimum yer ivmesi değerlerinin Gülkan ve Kalkan [52] azalım ilişkisine göre $0,10 \mathrm{~g}-0,50 \mathrm{~g}$, Boore vd., [57] azalım ilişkisine göre $0,05 \mathrm{~g}-0,60 \mathrm{~g}$ arasında değiştiği belirlenmiştir. Olasılık yöntemi kullanılarak yapılan hesaplamalarda Ankara il sınırları içinde 50 yılda \%10 aşılma olasılığına sahip maksimum yer ivmesi değerlerinin Gülkan ve Kalkan [52] azalım ilişkisine göre 0,20 g - 0,40 g, Boore vd., [57] azalım ilişkisine göre $0,05 \mathrm{~g}-0,25 \mathrm{~g}$ arasında değiştiği belirlenmiştir.

Halen yürürlükte olan 1996 tarihli resmi Türkiye Deprem Bölgeleri haritasına göre Ankara ilinin $\% 38$ 'inde 50 yılda \%10 aşılma olasılığına sahip maksimum yer ivmesi değerlerinin $0,1 \mathrm{~g}-0,2 \mathrm{~g}$, $\% 33$ 'ünde $0,2 \mathrm{~g}-0,3 \mathrm{~g}, \% 21$ 'inde $0,3 \mathrm{~g}-0,4 \mathrm{~g}$ ve $\% 8$ 'inde $\geq 0,4 \mathrm{~g}$ arasında değiştiği görülmektedir. Bu çalışma kapsamında yeni veriler 1şı̆̆ında yapılmış olan haritaya göre ise Ankara ilinin \%73'ünde 50 yılda \%10 aşılma olasılığına sahip maksimum yer ivmesi değerleri $0,2 \mathrm{~g}-0,3 \mathrm{~g}$ arasında, \%27'sinde ise $0,30 \mathrm{~g}-0,40 \mathrm{~g}$ arasında değişmektedir (Şekil 7). Halen yürürlükte olan 1996 tarihli resmi Türkiye Deprem Bölgeleri haritası hazırlanırken deprem üretme potansiyeli olan 17 kaynak bölge belirlenmiş ve hesaplamalar buna göre yapılmıştır. Yeni verilerin 1şığında ve sadece Ankara ilini kapsayacak şekilde yapılan bu çalışmada Dodurga fay zonu, Eldivan Elmadağ tektonik kaması, Bala, Cihanbeyli Yeniceoba, Kızılırmak, Seyfe ve Ezinepazarı fay zonu gibi yeni kaynak bölgeler tanımlanmıştır. Diğer etkenlerin yanı sıra yeni kaynak bölgeleri de Ankara il sınırları içinde olasılıksal ve deterministik yönteme göre beklenen yer ivmesi değerlerinin yüksek çıkmasında önemli rol oynamıştır.

$\mathrm{Bu}$ çalışma ile elde edilen deprem tehlike haritalarının Ankara ili için hazırlanacak olan bölgesel planlar, çevre düzeni planları, imar planları, acil durum planları, deprem senaryosu, zarar azaltma stratejik planları gibi çalışmalarda kullanılması önerilir. Çalışma kapsamında hesaplanmış maksimum yer ivmeleri ana kayadaki yer ivmesini göstermektedir. Özellikle imar planına esas jeolojik jeoteknik etüt ve zemin etütleri gibi çalışmalarda bu değerler kullanılırken zemin etkisinin de dikkate alınması gerekir.

\section{KAYNAKLAR (REFERENCES)}

1. BİB (Bayındırlık ve İskân Bakanlığı), Türkiye Deprem Bölgeleri Haritası, 1996.

2. Tabban, A., "Ankara'nın Deprem Bölgesinde Bulunmasının Nedenleri”, Deprem Araştırma Enstitüsü Bülteni, Cilt 3, No 14, 1-33, 1976.

3. Ergünay, O., "Sismik Tehlike Açısından Ankara'ya Genel Bakış", Yerbilimleri Açısından Ankara'nın Sorunları Simpozyumu, Ankara, 88-94, 1978.

4. Çetinkaya, N.N., Durgunoğlu, H.T., Kulaç, H.F. ve Karadayılar, T., "Ankara, İstanbul ve İzmir Bölgeleri Deprem Riski Analizi Karşılaştırmaları", İkinci Ulusal Deprem Mühendisliği Konferansı, İstanbul, 539-546, 1993.

5. Kasapoğlu, K.E., Ankara Kenti Zeminlerinin Jeoteknik Özellikleri ve Depremselliği, TMMOB Jeoloji Mühendisleri Odası Yayınları, Yayın no 54, Ankara, 2000.

6. Pampal, S. ve Kozlu, B., “Ankara'nın Depremselliği”, Türkiye Mühendislik Haberleri, Cilt 45, No 409, 25-31, 2000.

7. Koçyiğit, A., "Orta Anadolu'nun Genel Neotektonik Özellikleri ve Depremselliği”, Haymana-Tuzgölü-Ulukışla Basenleri Uygulamalı Çalışma (Workshop), Aksaray, 126, 9-11 Ekim 2000.

8. Koçyiğit, A., “Ankara’nın Depremselliği ve 2005-2007 Afşar (Bala-Ankara) Depremlerinin Kaynağı”, MTA Doğal Kaynaklar ve Ekonomi Bülteni, No 6, 1-7, 2008.

9. Kaplan, T., Neotectonics and Seismicity of the Ankara Region: A Case Study in the Uruş Area, Yüksek Lisans Tezi, Orta Doğu Teknik Üniversitesi, 2004. 
10. Seyitoğlu, G., Işık, V., Kırman, E. ve İleri, İ., Gölbaşı - Elmadă̆ Güneyinin Neotektonik Özellikleri, Ankara Üniversitesi Bilimsel Araştırma Projesi Kesin Raporu, Ankara, 2006.

11. Dirik, K., Özsayın, E. ve Kutluay, A., "Son Üç Yıldır Ankara Güneyinde (Orta Anadolu) Meydana Gelen Sismik Hareketliliğin Kaynakları", 61.Türkiye Jeoloji Kurultayı, Ankara, 76-77, 24-28 Mart 2008.

12. Utku, M., "Ankara'da Deprem Tehlikesi", Cumhuriyet Bilim ve Teknoloji, Cilt 21, No 1086, 6-7, 2008.

13. Kalafat, D., Kekoval1, D., Deniz, P., Güneş, Y., Pınar, A. ve Horosan, G., "31 Temmuz 2005 - 1 Ağustos 2005 ve 20 - 27 Aralık 2007 Afşar-Bala (Ankara) Deprem Dizisi”, İstanbul Yerbilimleri Dergisi, Cilt 21, No 2, 47-60, 2008.

14. Gökten, E. ve Varol, B., "Bölgenin Genel Jeolojisi ve Sismik Kaynakları", Ankara Kenti Batısındaki Zeminlerin Jeolojik-JeofizikJeoteknik Özellikleri ve Dinamik Davranışı, No 270, Editör: Ahmet Tuğrul Başokur, Ankara Üniversitesi, Ankara, 12-32, 2010.

15. Radulian, M., Vaccari, F., Mandrescu, N., Panza, G.F. ve Moldoveanu, C.L., "Seismic Hazard of Romania: Deterministic Approach", Pure Appl. Geophys., No 157, 221-247, 2000.

16. El-Sayed, A., Vaccari, F. ve Panza, G.F., "Deterministic Seismic Hazard in Egypt", Geophys. J. Int., No 144, 555-567, 2001.

17. Bulajic, B. ve Manic, M., "Selection of the Appropriate Methodology fort he Deterministic Seismic Hazard Assessment on the Territory of the Republic of Serbia, Facta Universitatis Architecture and Civil Engineering, Cilt 4, No 1, 41-50, 2006.

18. Joshi, A., Mohan, K. ve Patel, R.C., "A Deterministic Approach for Preparation of Seismic Hazard Maps in North East India", Natural Hazards, Cilt 43, No 1, 129-146, 2007.

19. Moratto, L., Orlecka-Sikora, B., Costa, G., Suhadolc, P., Papaioannou, Ch. ve Papazachos, C.B., "A Deterministic Seismic Hazard Analysis for Shallow Earthquakes in Greece", Tectonophysics, Cilt 444, No 1-4, 66-82, 2007.

20. Ganapathy, G.P., "A Deterministic Seismic Hazard Analysis for the Major Cultural Heritage Sites of Tamil Nadu, India", International Journal of Geomatics and Geosciences, Cilt 1, No 3, 529-543, 2010.

21. Tsapanos, T.M., Koravos, G.C., Zygouri, V., Tsapanos, M.T., Kortsari, A.N., Kijko, A. ve Kalogirou, E.E., "Deterministic Seismic Hazard Analysis fort he City of Corinth-Central Greece", Journal of Balkan Geophysical Society, Cilt 14, No 1, 1-14, 2011.

22. Tavakoli, H.R. ve Amiri, M.T., "Probabilistic and Deterministic Seismic Hazard Assessment in Amol Center, a City in North of Iran", Iranica
Journal of Energy \& Environment, Cilt 3, No 3, 259-263, 2012.

23. Shukla, J. ve Choudhury, D., "Estimation of Seismic Ground Motions Using Deterministic Approach for Major Cities of Gujarat", Nat. Hazards Earth Syst. Sci., Cilt 12, No 6, 20192037, 2012.

24. Wang, J.P., Huang, D. ve Yang, Z., "Deterministic Seismic Hazard Map for Taiwan Developed Using an in-house Excel-based Program", Computers \& Geosciences, Cilt 48, 111-116, 2012.

25. Kayabalı, K. ve Akın, M., "Seismic Hazard Map of Turkey Using the Deterministic Approach", Engineering Geology, Cilt 69, No 1-2, 127-137, 2003.

26. Tosun, H., Zorluer, İ., Orhan, A., Seyrek, E., Savaş, H. ve Türköz, M., "Seismic Hazard and Total Risk Analyses for Large Dams in Euphrates Basin, Turkey", Engineering Geology, Cilt 89, No 1-2, 155-170, 2007.

27. Seyrek, E., Orhan, A. ve Tosun, H., "Ceyhan Havzası Baraj Yerleri Deterministik Sismik Tehlike Analizi”, II. Ulusal Baraj Güvenliği Sempozyumu, Eskişehir, 575-582, 13-15 Mayıs 2009.

28. Tosun, H. ve Seyrek E., "Total Risk Analysis for Large Dams in Kızılırmak Basin, Turkey”, Nat. Hazards Earth Syst. Sci., Cilt 10, 979-987, 2010.

29. Seyrek, E. ve Tosun, H., "Deterministic Approach to the Seismic Hazard of Dam Sites in Kizilırmak Basin, Turkey", Nat Hazards, Cilt 59, 787-800, 2011.

30. Seyrek, E. ve Tosun, H., "Sismik Tehlike Analiz Yöntemlerinin Ülkemizdeki Büyük Beton Barajların Toplam Riski Üzerindeki Etkisi", Journal of the Faculty of Engineering and Architecture of Gazi University, Cilt 28, No 1, 67-75, 2013.

31. Kramer, S.L., Geoteknik Deprem Mühendisliği, Çeviren: Kamil Kayabalı, Gazi Kitabevi, Ankara, 2003.

32. Şaroğlu, F., Emre, Ö. ve Kuşçu, İ., "Türkiye Diri Fay Haritası", Maden Tetkik ve Arama Genel Müdürlüğü, 1992

33. Koçyiğit, A., "Changing Stress Orientation in Progressive Intracontinental Deformation as Indicated by the Neotectonics of the Ankara Region (NW Central Anatolia)", TPJD Bülteni, Cilt 3, No 1, 43-55, 1991.

34. Koçyiğit, A., Rojay, B., Cihan, M. ve Özacar, A., "The June 6, 2000 Orta (Çankırı, Turkey) Earthquake: Sourced from a New Antithetic Sinistral Strike-Slip Structure of the North Anatolian Fault System, the Dodurga Fault Zone", Turkish Journal of Earth Sciences, Cilt 10, No 2, 69-82, 2001. 
35. Koçyiğit, A. ve Deveci, Ş., “Ankara Orogenic Phase, Its Age and Transition From ThrustingDominated Palaeotectonic Period to the StrikeSlip Neotectonic Period, Ankara (Turkey)", Turkish Journal of Earth Sciences, Cilt 17, No 3, 433-459, 2008

36. Dirik, K., Çemen, İ. ve Göncüoğlu, M.C., "Neotectonics and Related Intracontinental Basin Formation in Central Anatolia - Turkey", International Conference on Active Tectonic Continental Basins, Belgium, 55, 30 Nisan, 2 Mayıs 1998.

37. Dirik, K., "Neotectonic Evolution of the Northwestward Arched Segment of the Central Anatolian Fault Zone, Central Anatolia, Turkey", Geodinamica Acta, Cilt 14, 147-158, 2001.

38. Dirik, K., Göncüoğlu, M.C., "Neotectonic Characteristics of Central Anatolia", Int. Geology Review, Cilt 38, 807-817, 1996.

39. Çemen, İ., Göncüoğlu, M.C. ve Dirik, K., "Structural Evolution of the Tuzgölü Basin in Central Anatolia, Turkey", Journal of Geology, Cilt 107, 693-706, 1999.

40. Eren, Y., "Konya Bölgesinin Depremselliğii", Haymana-Tuzgölü-Ulukışla Basenleri Uygulamalı Çalışma (Workshop), Aksaray, 8598, 9-11 Ekim 2000.

41. Özsayın, E. ve Dirik, K., "Quaternery Activity of the Cihanbeyli and Yeniceoba Fault Zones: İnönü - Eskişehir Fault System, Central Anatolia", Turkish Journal of Earth Sciences, Cilt 16, No 4, 471-492, 2007.

42. İnternet: AFAD (Başbakanlık Afet ve Acil Durum Yönetimi Başkanlığı), http://www.deprem.gov.tr/sarbis/Shared/Default. aspx, 2013.

43. İnternet: KANDİLLİ (Boğaziçi Üniversitesi Kandilli Rasathanesi ve Deprem Araştırma Enstitüsü),

http://www.koeri.boun.edu.tr/scripts/lst7.asp, 2013.

44. Erdik, M., Doyuran, V., Akkaş, N. ve Gülkan, P., "A Probabilistic Assessment of the Seismic Hazard in Turkey", Tectonophysics, Cilt 117, No 3-4, 295-344, 1985.

45. Gülkan, P., Koçyiğit, A., Yücemen, M.S., Doyuran, V. ve Başöz, N., 1993. En Son Verilere Göre Hazırlanan Türkiye Deprem Bölgeleri Haritası, No: METU/EERC 93-01, Orta Doğu Teknik Üniversitesi, Ankara, 1993.

46. TEFER (Turkey Emergency Flood and Earthquake Recovery Project), "Consulting Services for Improvement of Natural Hazard Insurance and Disaster Funding Strategy, Final Report, Pragramme 6.1 Review of Loss
Potential and Catastrophic Risk Modelling", Section 5, The Hazard of Earthquake, Başbakanlık Hazine ve Dış Ticaret MüsteşarlığıSigortacilık Genel Müdürlüğü, Ankara, 2001.

47. DLH (Ulaştırma Bakanlığı Demiryolları, Limanlar ve Havameydanları İnşaatı Genel Müdürlüğü), "Kıyı Yapıları, Demiryolları ve Havameydanları İnşaatları Deprem Teknik Yönetmeliği için Deprem Tehlikesi Belirlemesi”, YPU-DLH-060520-001-Ara rapor 1, Ankara, Yüksel Proje, 2007.

48. Özmen, B., Ankara'nın Deprem Tehlikesinin Belirlenmesi, Doktora Tezi, Gazi Üniversitesi, Fen Bilimleri Enstitüsü, 2011.

49. Deniz, A., Estimation of Earthquake Insurance Premium Rates Based on Stochastic Methods, Yüksek Lisans Tezi, Orta Doğu Teknik Üniversitesi, Fen Bilimleri Enstitüsü, Ankara, 2006.

50. İnan, E., Çolakoğlu, Z., Koç, N., Bayülke, N. ve Çoruh, E., 1976 - 1996 Yılları Arası İvme Kayıtları Olan Deprem Kataloğu, Afet İşleri Genel Müdürlüğü Deprem Araştırma Dairesi Başkanlı̆̆ı, Ankara, 1996.

51. Aydan, Ö., Sedaki, M. ve Yarar, R., "The Seismic Characteristics of Turkish Earthquakes", Eleventh World Conference on Earthquake Engineering, Mexico, 1-8, 23-28 Haziran 1996.

52. Gülkan, P. ve Kalkan, E., "Attenuation Modeling of Recent Earthquakes in Turkey", Journal of Seismology, Cilt 6, No 3, 397-409, 2002.

53. Kalkan, E. ve Gülkan, P., "Empirical Attenuation Equations for Vertical Ground Motion in Turkey", Earthquake Spectra, Cilt 20, No 3, 853-882, 2004.

54. Ulusay, R., Tuncay, E., Sönmez, H. ve Gökçeoğlu, C., "An Attenuation Relationship Based on Turkish Strong Motion Data and IsoAcceleration Map of Turkey", Engineering Geology, Cilt 74, No 3-4, 265-291, 2004.

55. Beyaz, T., Zemin Etkisinden Arındırılmış Deprem Kayıtlarına Göre Türkiye için Yeni Bir Deprem Enerjisi Azalım Bağıntısının Geliştirilmesi, Doktora Tezi, Ankara Üniversitesi, Fen Bilimleri Enstitüsü, 2004.

56. Yunatç1, A.A., GIS Based Seismic Hazard Mapping of Turkey, Doktora Tezi, Orta Doğu Teknik Üniversitesi, Fen Bilimleri Enstitüsü, 2010.

57. Boore, D.M., Joyner, W.B., Fumal, T.E., "Equations for Estimating Horizontal Response Spectra and Peak Acceleration from Western North American Earthquakes: A Summary of Recent Work", Seismological Research Letters, Cilt 68, No 1, 128-153, 1997. 